\title{
DRINKING WATER: AN ENVIRONMENTAL CHEMICAL APPROACH TO SECONDARY SCHOOL'S STUDENTS
}

\author{
PIRES, Ana Cristina Alves; FIELD’S, Karla Amâncio Pinto². \\ 1,2 Instituto Luterano de Ensino Superior de Itumbiara (ILES/ULBRA), Departamento de Química, Av. Beira Rio, \\ $n^{\circ}$ 1001, Bairro Nova Aurora CEP: 75523-200. Itumbiara - Goiás, Brasil \\ *e-mails:anacap1011@hotmail.com; kapf2@hotmail.com.
}

\section{RESUMO}

Este artigo tem como objetivo abordar a temática "Água potável no ensino de Química" possibilitando aos alunos a elaboração de um conceito de ciência como atividade humana e social, além de relacionar os principais aspectos do consumo de água potável com o desenvolvimento tecnológico e científico através de um enfoque Ciência, Tecnologia, Sociedade e Ambiente (CTSA). Utilizar a abordagem temática vinculando aspectos sociais e ambientais com os conteúdos trabalhados em sala de aula permite o desenvolvimento de valores e atitudes sendo imprescindível o envolvimento do tema com o cotidiano dos alunos. Nesse sentido, o presente trabalho trata do relato do primeiro encontro de um minicurso aplicado no Ensino Médio de uma escola pública da cidade de Itumbiara - Goiás. Essa etapa foi realizada através da metodologia participativa e da pesquisa-ação. As discussões sobre os conteúdos trabalhados e as experimentações com o uso da internet permitiram uma aprendizagem significativa com desenvolvimento e interação entre os alunos e o professor.

Palavras-chave: água potável, ensino de Química, enfoque CTSA.

\begin{abstract}
This article aims to approach the thematic: "Drinking Water" in teaching of chemistry, allowing the students to elaborate a concept of science as a human and social activity, relating the main aspects of the consumption of drinking water with technological and scientific development through science, technology, society and environment (STSE) focus. Using the thematic boarding, linking social and environmental aspects with the contents worked in the classroom, allows the development of values and attitudes essential to the theme's involvement in students' everyday life. So, this work deals with the account of the first meeting of a mini-course which took place at a secondary public school in Itumbiara city - Goiás. This stage was achieved through a participating methodology and action research. The discussions about the contents worked, and experimentation with the use of the Internet, provided a significant understanding along with the development and interaction amongst students and the teacher.
\end{abstract}

Keywords: drinking water. Teaching of chemistry . STSE focus. 


\section{Introdução}

Para Zuin, loriatti e Matheus (2009), os conteúdos aplicados no Ensino Médio devem conter temas que abordem questões científicas, tecnológicas, sociais e ambientais (enfoque CTSA - Ciência, Tecnologia, Sociedade e Ambiente). proporcionando a formação de cidadãos que tenham visão que contemplem estes aspectos.

Ensinar através dessa concepção CTSA permite o rompimento dos limites tradicionais de compreender o mundo, na aquisição de novos conhecimentos, habilidades e valores. Os estudantes passam a ser capazes de tomar decisões responsáveis sobre questões de ciência e tecnologia na sociedade e atuar na solução das mesmas.

Dessa forma, segundo Maciel e Domingues (2001), a sociedade deve estar envolvida com a preocupação de indicar a água como uma questão de Educação Ambiental, não só pela sua escassez, mas por preocupações com os mananciais, com as doenças decorrentes do uso de água poluída e com a exploração indiscriminada de muitos recursos hídricos, que prejudicam grande parcela da população.

De acordo com Lage, Nogueira e Foresti (2004), em muitos países, há altos níveis de perda no uso dos recursos hídricos, por exemplo, sendo intoleráveis e representando grandes desperdícios financeiros que poderiam ser investidos na resolução de problemas de abastecimento e tratamento da água para milhões de pessoas. Se os gestores dos recursos hídricos contarem com a participação ativa de uma comunidade devidamente esclarecida, as perdas poderão ser substancialmente reduzidas

A água, que normalmente encontra-se na natureza, sobre a superfície dos solos ou nas camadas subterrâneas, denomina-se de água bruta. Essa água, após tratamento conveniente, é denominada tratada e atendendo aos parâmetros fixados pelo padrão de potabilidade, denomina-se potável.

A Portaria $n^{\circ}$ 518/2004 do Ministério da Saúde, define em seu artigo. $4^{\circ}$, como sendo água potável para consumo humano, aquela que atende os parâmetros microbiológicos, físicos, químicos e radioativos do padrão de potabilidade e que não ofereça riscos à saúde (BRASIL, 2004).

Dessa forma, alguns parâmetros da água de ordens física e química, que normalmente são investigados para se qualificar um dado tipo de água potável são turbidez, cor, $\mathrm{pH}$ e cloro e flúor.

A Turbidez representa os sólidos em suspensão presentes na água. Em relação às características físicas, Daniel (2001) diz que a turbidez desempenha papel predominante na eficiência da desinfecção, promovendo efeito escudo sobre os microrganismos e protegendoos da ação do desinfetante. Diversas pesquisas confirmaram menor inativação de coliformes na desinfecção com compostos de cloro, quando a turbidez elevava-se acima de 1,0 UT (Unidade de Turbidez).

A Cor da água na natureza é o resultado, principalmente, dos processos de decomposição da matéria orgânica, da presença de alguns íons metálicos como ferro e manganês e de material em suspensão (LAURENTI, 1997).

$\mathrm{O} \mathrm{pH}$ é usado universalmente para exprimir a intensidade com que determinada solução é ácida ou alcalina, considerando-se que se $0 \mathrm{pH}$ da solução for inferior a 7, trata-se, portanto, de uma solução ácida e se seu pH for superior a 7 então a solução será considerada alcalina. Logo uma solução, cujo pH é igual a 7 , é neutra (GOIÁS, 2006).

A Portaria $n^{\circ}$ 518/2004 relata em seu artigo 13, que, após a desinfecção, a água deve conter um teor mínimo de cloro residual livre de $0,5 \mathrm{mg} / \mathrm{L}$. É obrigatória à manutenção de, no mínimo, $0,2 \mathrm{mg} / \mathrm{L}$ em qualquer ponto da rede de distribuição e o teor máximo de cloro residual livre, em qualquer ponto do sistema de abastecimento, seja de 2,0 mg/L (BRASIL, 2004).

Segundo consta em Goiás (2006), no Brasil, em sistemas de abastecimento em que existe estação de tratamento, a fluoretação da água é obrigatória, de acordo com a Lei Federal $n^{\circ} 6050$, de $24 / 05 / 74$, que foi regulamentada pelo Decreto Federal $n^{\circ} 76872$, de 22/12/75.

Pretendeu-se com esta pesquisa realizar com os alunos o estudo da água potável, enfocando conceitos químicos, verificando sua aplicabilidade para o Ensino Médio. Objetivou-se ainda:

-possibilitar aos alunos a elaboração de um conceito de ciência como atividade humana e social e que, portanto, ultrapassa a aplicação rigorosa de métodos e técnicas, envolvendo percepção, curiosidade e questionamento;

-correlacionar os principais aspectos da importância da água para a vida, e seu uso nas atividades antropológicas, com o 
desenvolvimento social, tecnológico e científico, reconhecendo seus limites éticos e morais;

-motivá-los e conscientizá-los à valorizarem e fazerem uso racional da água potável.

\section{Materiais e Métodos}

O presente trabalho trata do relato do $1^{\circ}$ primeiro de seis encontros, componentes de um minicurso, o qual foi desenvolvido por meio de levantamentos bibliográficos, com revisão de literatura em revistas científicas, livros e sites oficiais da área de Ensino e de Saneamento para a fundamentação do trabalho bem como, através da aplicação de um minicurso, com carga horária de 24 horas-aula.

O minicurso foi promovido em uma escola da rede estadual de ensino, predominantemente de baixa renda, localizada na cidade de Itumbiara - Goiás. Foram oferecidas 20 vagas para todos os estudantes do Ensino Médio, tanto do turno matutino, quanto do turno noturno, oportunizando, dessa forma, um evento diferenciado das aulas rotineiras, possibilitando ainda uma visão mais simples e clara dos conteúdos químicos por meio de um tema organizador: Água potável.

O encontro foi realizado através da metodologia participativa e da pesquisa-ação em estudos da área sócio-ambiental, no contexto escolar.

Assim, nesta metodologia planeja-se, implementa-se, descreve-se e avalia-se uma mudança para o aprimoramento de sua prática, aprendendo mais, no correr do processo, tanto a respeito da prática quanto da própria investigação (TRIPP, 2005, p. 445- 446).

\section{Resultados e Discussões}

Durante o primeiro encontro do minicurso foram desenvolvidas inúmeras atividades em forma de exercícios, trabalhos artísticos, leituras, produções escritas e discussões em grupos, as quais possibilitaram a coleta dos dados.

Inicialmente, foi feita a apresentação da estagiária aos alunos. Em seguida, foi realizada a dinâmica: "Ofereça um copo com água", para que fosse introduzido o tema, de forma que, todos os alunos se apresentassem, ofertando um copo (copinhos de água cedidos pela empresa de saneamento), contendo água, a outro aluno, sendo que, quando ele ofertasse o copo, ele deveria dizer para o outro o porquê este mereceria ter sempre água potável disponível.

Essa dinâmica, aplicada no início do minicurso, serviu como uma estratégia de ensino, de modo a fazer com que os alunos fossem inseridos na temática, que seria abordada durante toda semana e também para que os alunos e a estagiária se conhecessem melhor, já que era uma turma heterogênea, com alunos de todos os anos dos turnos matutino e noturno.

Percebeu-se que as dinâmicas contribuem para que o aprendizado se efetive de forma satisfatória, favorecendo uma maior interatividade na relação professor e aluno.

Posteriormente, a estagiária distribuiu lápis de cor, canetinhas e folhas A4 aos alunos e pediu-os que elaborassem desenhos livres e diversos, relacionando-os com três palavras: "ÁGUA POTÁVEL + USO RACIONAL = SAÚDE". Nas folhas estavam impressas, além dessas três palavras, mandalas, que eram formas prontas, no formato de uma estrela de oito pontas, espaços nos quais os alunos realizariam os desenhos.

Mediante a interpretação das palavras e relacionando-as com as formas de utilização da água em seus cotidianos, os alunos elaborariam seus desenhos para que a estagiária verificasse qual era a compreensão inicial que eles tinham sobre o tema do minicurso.

A utilização das mandalas teve como finalidade explorar o conhecimento prévio dos alunos, além de que é um método utilizado para enriquecer a aula com exemplo prático.

Segundo Elisei (2008), esse tipo de atividade permiti ao aluno desenvolver habilidades e competências de representar códigos, signos, desenvolve a criatividade e ainda verifica a capacidade de interpretar a proposta dada, que nesse caso seria realizar um desenho mediante a interpretação dos termos dados junto da mandala.

Ao analisar as mandalas, foi possível constatar que alguns alunos tinham uma vaga percepção sobre uso racional de água potável, enquanto outros fizeram uma correlação socioambiental com a proteção do meio ambiente. Mas alguns já traziam consigo um conhecimento prévio relativamente considerável.

$\mathrm{Na}$ análise das mandalas 1 e 2, notou-se que os alunos apresentaram um conceito reduzido sobre uso racional de água potável, 
demonstraram ainda dificuldade em expressar a idéia central da atividade, mas os alunos justificaram segundo as experiências deles, que, água potável era aquela que se podia beber e que todos precisam dela.

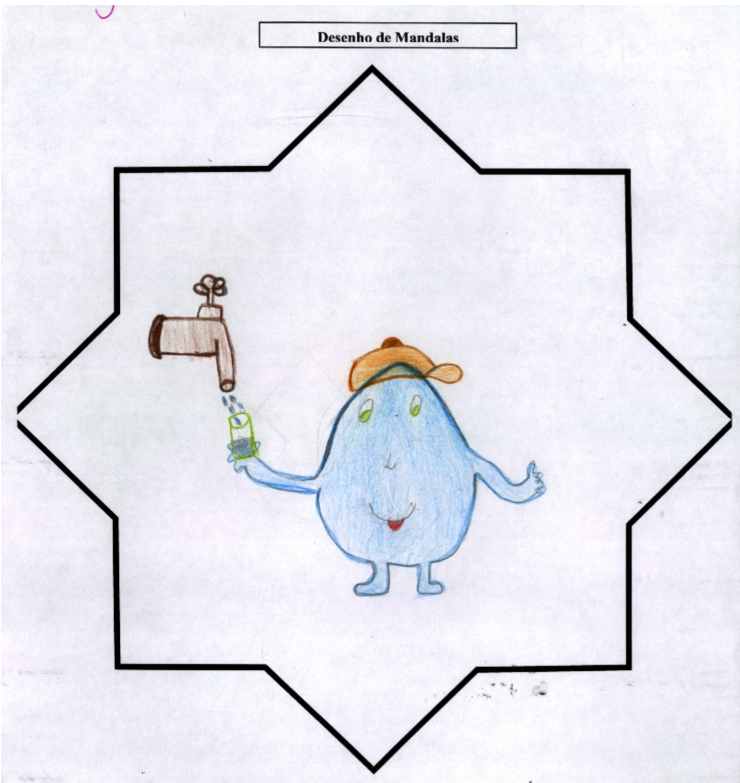

Água potável + Uso racional = Saúde

Figura 1 - Mandala 1.

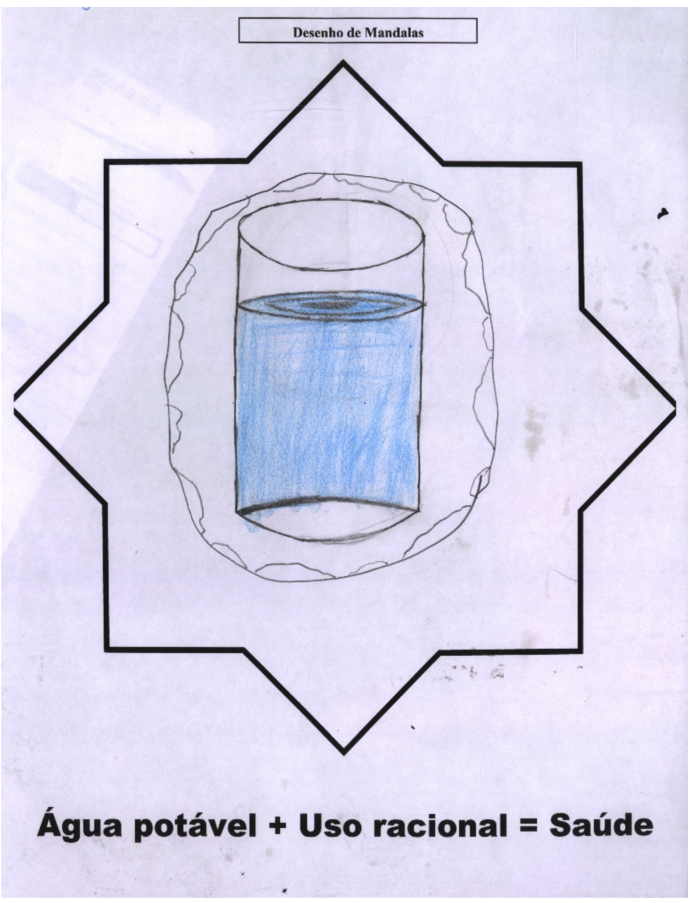

Figura 2 - Mandala 2.

Na Mandala 3, o aluno fez ligação do uso racional com a proteção do meio ambiente, assim como na Mandala 4 observou-se a mesma preocupação em preservação dos recursos hídricos.

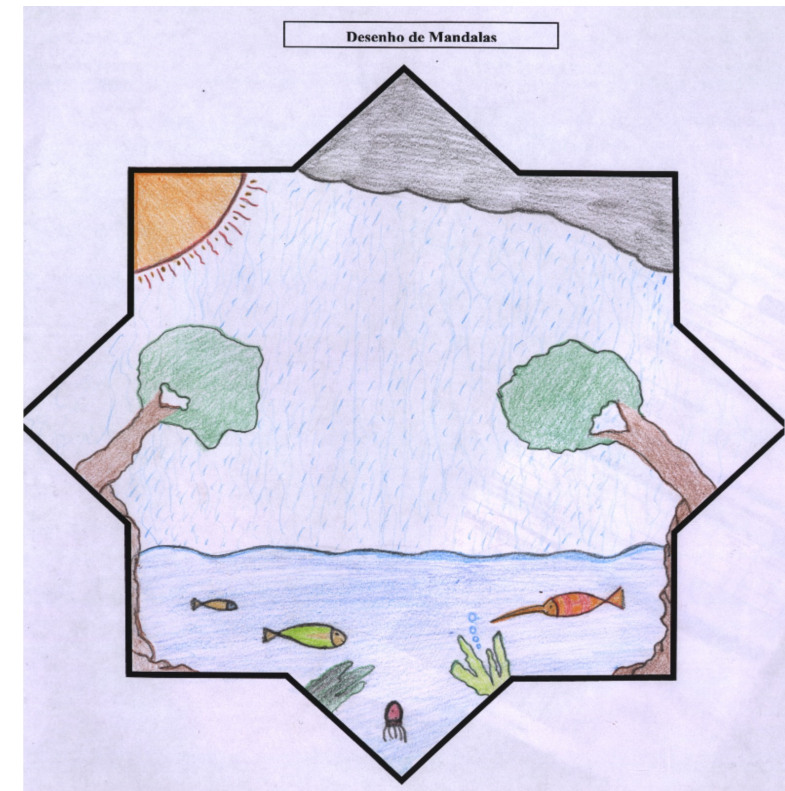

\section{Água potável + Uso racional = Saúde}

Figura 3 - Mandala 3.

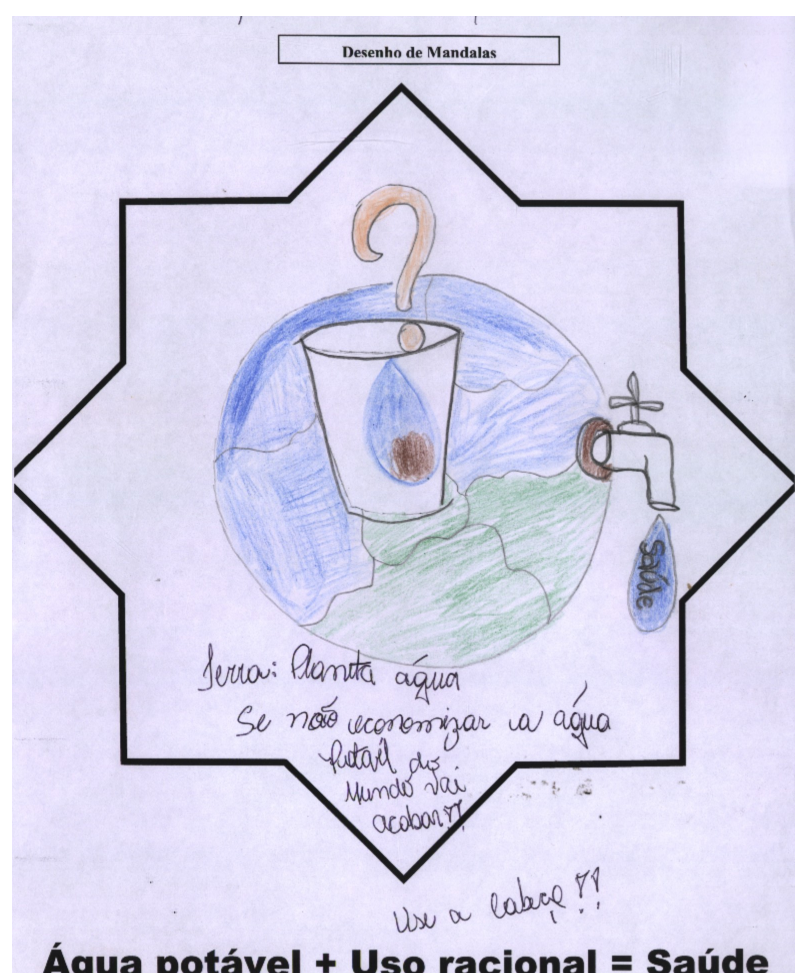

Figura 4 - Mandala 4.

Nas mandalas 5 e 6 percebeu-se que os alunos apresentaram um conhecimento mais elaborado sobre a utilização da água nas atividades humanas e que esse uso deve ser feito de forma racional e consciente, utilizando 
água tratada, economizando, para que sempre se tenha água de boa qualidade e consequentemente a preservação da saúde.

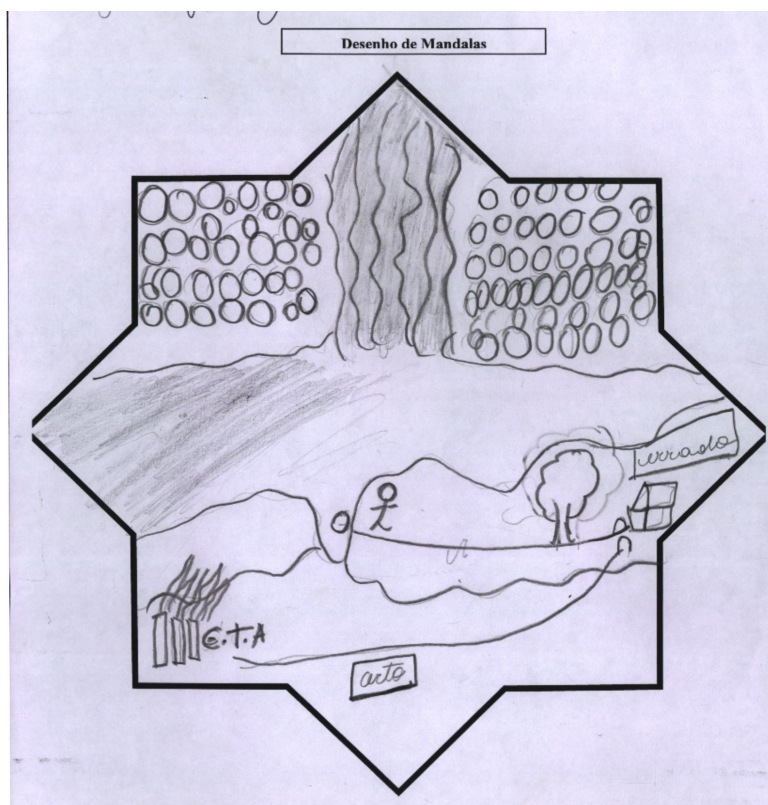

Água potável + Uso racional = Saúde

Figura 5 - Mandala 5.

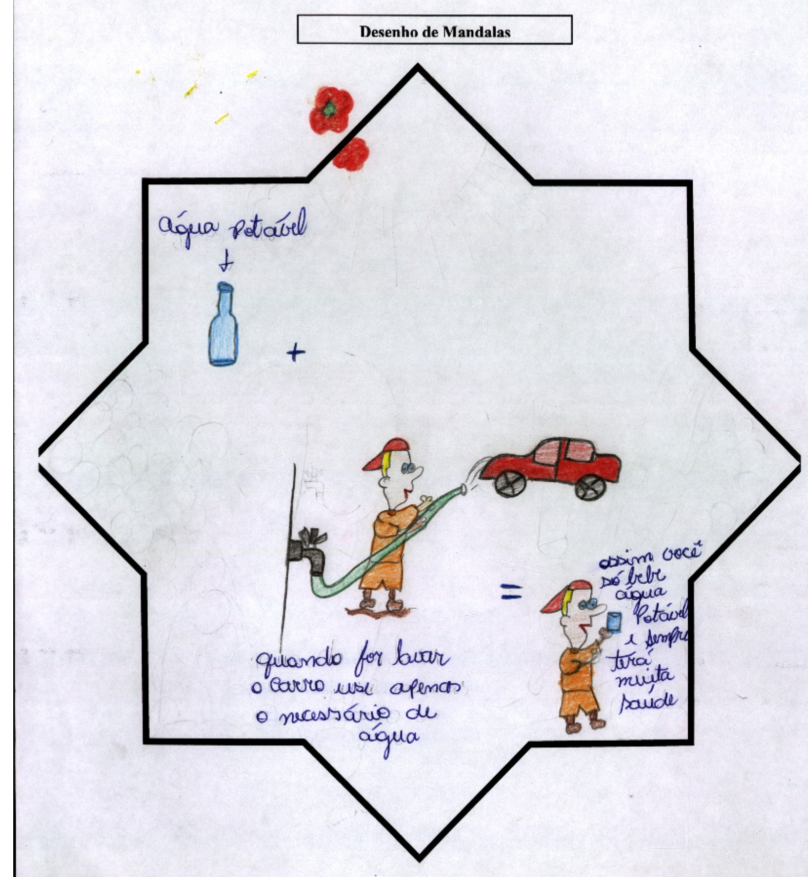

Água potável + Uso racional $=$ Saúde

Figura 6 - Mandala 6.

Em seguida, a estagiária fixou um cartaz contendo um mapa conceitual no quadro negro e explicou brevemente alguns tópicos que seriam trabalhados.

$\mathrm{Na}$ medida em que os alunos utilizarem mapas conceituais para integrar, reconciliar $e$ diferenciar conceitos e também usarem essa técnica para analisar artigos, textos, capítulos de livros, romances, experimentos de laboratório, e outros materiais educativos do currículo, eles estarão usando o mapeamento conceitual como um recurso de aprendizagem [MOREIRA, 1997, p.5].

Foi explicado, através do mapa, o qual pode ser observado pela Figura 7 , que a água para ser considerada potável deve passar por tratamentos, os quais podem ser físicos e/ou químicos. Somente os tratamentos é que podem dizer se ela está própria para o consumo. Para tanto faz-se necessário efetuar um controle de qualidade, que se constitui por análises físicoquímicas e bacteriológicas. Desta forma, a população consumirá uma água de qualidade, estará satisfeita, com a saúde garantida e a empresa de saneamento cumprirá essas etapas, na produção de água potável, e atendendo aos órgãos fiscalizadores, mas foi ressaltado que todo o processo exige um custo para com produção e gastos de recursos financeiros e humanos.

Em seguida, foi pedido aos alunos que ligassem os computadores, já que a aula foi realizada na sala de informática, e que acessassem o site da empresa de saneamento da cidade (SANEAGO), clicando no ícone: "Entenda sua conta de água". No site, através do ícone podia-se observar um modelo fictício de conta de água. Ao se mover o mouse pelos itens da conta, aparecia um balão com um texto explicativo sobre cada item, o qual era lido e explicado pela estagiária juntamente com os alunos.

Foi muito produtivo utilizar esse recurso didático, pois sabe-se que o uso da Internet no ensino tira o caráter de conhecedor-único do professor, conduzindo a um novo modelo no qual a responsabilidade pelo aprendizado passa pela busca individual do estudante. Para isso a escola tem que estar estruturada e o professor preparado para este novo tipo de interação com o estudante. A Internet pode ter um papel fundamental neste ambiente de troca. Assim como livros, visitas técnicas, pesquisa de campo, periódicos, vídeos, e seminários dão suporte a formação do estudante, a Internet também pode ser utilizada no processo de ensinoaprendizagem. Neste processo, os professores 
continuarão a ser os responsáveis em avaliar e decidir como a Internet poderá ser utilizada como ferramenta na sua aula [FERREIRA, 1998, p. 782].

A estagiária ainda distribuiu contas de água, caso a conexão da internet não fosse boa e também para complementar o estudo dos itens da conta, como, por exemplo, os tipos de análises realizadas para garantia da qualidade $\mathrm{e}$ seus respectivos significados e também a prestação de serviço social realizada pela empresa, quando se observa a divulgação de fotos de crianças desaparecidas no verso da conta.

Pela Figura 8, podemos analisar que a conta de água, proporciona trabalhar diversos pontos relevantes, não só para o ensino de Química, como também para a formação da cidadania.

Pagar nossos tributos faz parte da vida cotidiana, mas exigir nossos direitos também, e muitas vezes por não saber interpretar alguns dados presentes nesse tipo de tributo, o cidadão não consegue exigir seus direitos, em relação ao consumo de água. $\mathrm{O}$ consumidor, em algumas circunstâncias, não consegue interpretar informações a respeito da qualidade do seu produto.

Ainda, utilizando-se o computador e abordando esse assunto, foi explicado que existem diversos tipos de tarifas e que estas estão relacionadas com o gasto de água, e que são classificadas em diferentes categorias como, por exemplo, a tarifa social (para pessoas de baixa renda), tarifa residencial, tarifa comercial e tarifa industrial. Esta explicação gerou muita discussão, pois muitos alunos disseram que seus pais sempre reclamavam que a tarifa de água era cara, sem compreender o motivo do custo. Então, foi explicado que no valor da água potável está inserido todo o processo de captação, tratamento e distribuição, já que a água que se encontra na natureza está no estado bruto.

Ressaltou-se ainda que, existem gastos com energia devido ao bombeamento da água do rio (água bruta) até a Estação de Tratamento de Água (E.T.A.) e, depois, o bombeamento da água potável até as casas, além da quantidade de pessoas que trabalhavam nessa produção de água.

Ao descrever os itens que são cobrados na conta, a maioria dos alunos ficou indignada por se cobrar pela coleta de esgoto perguntando: "Se a água suja e já que vai se jogar fora, então para que se cobrar?". A estagiária respondeu que a cobrança é devida a coleta em tubulações, para que o esgoto não corra a céu aberto e para que ele seja enviado até uma Estação de Tratamento de Esgotos (E.T.E.).

Em relação ao histórico de consumo e a média de consumo ( $\left.\mathrm{m}^{3} / \mathrm{mês}\right)$, perguntou-se aos alunos se eles tinham noção do quanto representava essa quantidade consumida, porém eles não sabiam, de fato, por não compreenderem a unidade de medida $\mathrm{m}^{3}$.

Nesse momento a estagiária teve que recorrer à Matemática e explicar no quadro sobre um pouco do conteúdo de Potenciação. Ela informou que a água consumida estava no estado líquido, portanto, ocupava um volume e que, a medida de volume é dada em Litro e seus múltiplos e submúltiplos ou dada em $\mathrm{m}^{3}$. Quando ela perguntou se eles sabiam ou para os que já haviam estudado se eles se lembravam dessa unidade a resposta foi unânime: NÃO.

Logo, a estagiária percebeu que os alunos tinham dificuldades em Matemática, especificamente, sobre Potência, que é um prérequisito nessa fase do ensino, para muitas disciplinas.

Assim, ela explicou que, como a água está no estado líquido, ela ocupa um espaço de um dado recipiente, quer seja um copo, uma caixa de água, um reservatório, os quais podem ter diferentes formas geométricas.

Por meio da exemplificação, do formato geométrico sala de aula que é um paralelepípedo, a estagiária explicou, dizendo que se fosse possível lacrar todas as janelas da sala e enchê-la com água, esta ocuparia, inicialmente, toda a área $\left(\mathrm{m}^{2}\right)$, a qual era formada pelo comprimento (em $\mathrm{m}$ ), multiplicado pela largura da sala (em $\mathrm{m}$ ), mas como o nível de água aumentaria com o decorrer do tempo, essa água alcançaria a altura das paredes $(\mathrm{m})$. Logo, $\mathrm{m}^{2}$ multiplicado por metro $(\mathrm{m})$ ter-se-ia o volume total de água na sala, ou seja, $\mathrm{m}^{3}$. Ainda foi descrito que o volume a ser calculado poderia ser de qualquer forma geométrica, como um cubo, um paralelepípedo, um cilindro, entre outras formas.

Então, a estagiária percebeu que os alunos haviam entendido sobre a medida de volume, mas ainda não tinham uma noção dessa quantidade.

Foi necessário explicar que $1 \mathrm{~m}^{3}$ equivale a $1000 \mathrm{~L}$, ou seja, que seria necessário ter-se 500 garrafas PETs de refrigerantes de $2 \mathrm{~L}$ cheias 
para se ter $1 \mathrm{~m}^{3}$ de água, por exemplo, e que muitas pessoas gastavam por dia muito mais do que isso. Os alunos ficaram surpresos ao terem noção da quantidade de água equivalente a $1 \mathrm{~m}^{3}$.

Foi possível notar que quando se exemplifica um dado conteúdo para os alunos com aspectos (sala de aula) e materiais (garrafas de refrigerantes de $2 \mathrm{~L}$ ) os alunos compreendem com mais facilidade e muito mais rápido do que quando se explica utilizando apenas as teorias dos livros didáticos.

Devido ao fato de que no município onde foi aplicado o minicurso, ter um rio importante para a região (o Rio Paranaíba), muitos alunos perguntaram:

- "Se a cidade tem um rio tão grande, além de outros rios afluentes deste, então porque a água não pode ter um preço bem mais baixo?" Então a estagiária respondeu:

-"A água que a cidade consome não é a desse rio, mas mesmo assim, independente do manancial, a água deve ser captada, tratada e distribuída e dessa forma existe um custo alto para que essas etapas sejam realizadas."

Assim, foram explicados os conceitos de água bruta, tratada e potável. Isso gerou muita discussão, porque os alguns alunos achavam que se a água estivesse com aspecto limpo e transparente, estaria própria para consumo e ainda, outros alunos achavam que a água de cisterna também por apresentar-se limpa, ela podia ser consumida. Então, a estagiária explicou que os microrganismos que transmitem doenças podem estar presentes na água mesmo que ela esteja com aspecto límpido.

Sobre os parâmetros citados na conta (Cloro, Flúor, Turbidez, Cor, pH, Coliformes totais e Coliformes termotolerantes), notou-se que os alunos quase ou praticamente não tinham conhecimento sobre eles. A Cor foi o item mais explicado pela maioria deles, associando-se os termos: transparente, suja, barrenta, a boa ou má qualidade da água. Outro item que alguns alunos disseram ter ouvido falar era os Coliformes, citados muitas vezes na televisão por um programa que analisa os produtos consumidos e ambientes muito frequentados pela população. Eles disseram que o "doutor" que aparece na TV diz que os coliformes são "bichinhos" muito pequenos que causam doenças.

A estagiária disse então que todos esses parâmetros mencionados na conta indicavam alguma característica que a água potável deve apresentar para estar própria para o consumo e que a empresa divulga essas informações em conformidade com a lei e em respeito ao consumidor, o qual tem o direito de saber que consome uma água de qualidade.

Ela explicou brevemente e de forma mais simplificada cada parâmetro detalhado na conta.

Através do uso do computador conectado a internet, trabalhando-se com a conta de água, exemplificada no site da empresa de saneamento, a estagiária conseguiu fazer com que os alunos se interessassem mais pela aula, e que, portanto, tivessem uma maior participação neste $1^{\circ}$ encontro.

Ferreira (1998) relata que se as escolas e universidades pretendem formar cidadãos para se integrarem na sociedade, a questão do uso das novas tecnologias na escola não significaria apenas um modismo. E ainda, a utilização destes recursos ajuda a formar cidadãos e trabalhadores mais preparados funcionalmente (capital humano), pois em muitas áreas da sociedade estas tecnologias já estão a muito tempo em utilização (indústrias, comércio, transportes, bancos, etc.) [DIMENSTEIN, 1997 apud FERREIRA, 1998, . p. 781].

Nesse encontro, também foi solicitado aos alunos que acessassem o site do YouTube, buscando o vídeo: "Água: fonte da vida!", para enfatizar, então, a importância de se preservar a água.

O vídeo, além de conter mensagens sobre a composição dos seres vivos e do meio ambiente por grandes porcentagens de água, ainda mostrava a distribuição e utilização da água em diversas atividades humanas. $O$ vídeo também possuía um áudio da música Planeta Água, sendo que a letra esta transcrita abaixo, pela qual podemos observar que enfatiza os cursos que a água percorre no mundo (que é o ciclo água) e também sua relevância para a humanidade.

Ainda, o vídeo apresentava várias frases explicando que a humanidade que faz uso da água deve se lembrar que a mesma é um recurso limitado.

Os alunos, por meio do vídeo foram alertados da importância de se ter e fazer uso racional da água, até mesmo para se evitar danos ao homem, por suas próprias ações indevidas, causando desastres como as inundações, contaminações e/ou escassez de água.

Após assistir ao vídeo, os alunos relataram sua compreensão sobre o mesmo, 
além de mencionarem que o vídeo reforçava e facilitava os estudos sobre a água, por apresentar um texto no vídeo com um conteúdo bom e de fácil entendimento.

A intenção em utilizar o filme como recurso didático era justamente de dispertar a conscientização ambiental dos alunos e a importancia de se ter água potável. A estagiária percebeu que o filme estimulou os alunos a observarem diversas questões como o desperdício de água, as pessoas que sofrem com a sua escassez,entre outros pontos citados pelos alunos como relevântes.

Uma aluna disse:

- "Professora só a música já diz tudo, sem água o que seria do nosso planeta?"

A música e os efeitos sonoros servem como evocação, lembrança (de situações passadas), de ilustração, associados a personagens do presente, como nas telenovelas, e de criação de expectativas, antecipando reações e informações. O vídeo é também escrita. Os textos, legendas, citações aparecem cada vez mais na tela, principalmente nas traduções (legendas de filmes) e nas entrevistas com estrangeiros. A escrita na tela hoje é fácil através do gerador de caracteres, que permite colocar na tela textos coloridos, de vários tamanhos e com rapidez, fixando ainda mais a significação atribuída à narrativa falada. $O$ vídeo é sensorial, visual, linguagem falada, linguagem musical e escrita. Linguagens que interagem superpostas, interligadas, somadas, não separadas. Daí a sua força. Nos atingem por todos os sentidos e de todas as maneiras. O vídeo nos seduz, informa, entretém, projeta em outras realidades (no imaginário) em outros tempos e espaços. O vídeo combina a comunicação sensorial-cinestésica, com a audiovisual, a intuição com a lógica, a emoção com a razão. Combina, mas começa pelo sensorial, pelo emocional e pelo intuitivo, para atingir posteriormente o racional [MORAN, 1995, p. 30].

Ao se planejarem aulas em que se utilizará a internet deve-se verificar onde a aula será ministrada e se esse recurso permite um uso acessível.

Souza et al., (2009) mencionam que é fundamental correlacionar os elementos que remetem à realidade em que estudantes e professores estão inclusos com as formas tradicionais de ensino.

Trazendo as novas tecnologias para o contexto dos vídeos do YouTube, podemos afirmar que a ferramenta pode ser uma grande aliada dos professores e alunos, mas que deve ser trabalhado com um planejamento adequado, utilizado apenas como acessório e não como única ferramenta, até porque alguns alunos ainda compreende o YouTube como uma forma de entretenimento e não assimilam sua verdadeira utilização pelos profissionais da educação [SOUZA et al., 2009, p. 7].

Ao final do encontro, foi pedido aos alunos que desenvolvessem uma redação, para verificação da capacidade de relacionar os itens trabalhados no encontro. Essa redação tinha como tema "Formas de economizar água no nosso cotidiano.

$\mathrm{Na}$ correção das redações foi possível verificar que houve adequação à proposta em todas as redações, bem como coerência com o tema escolhido, clareza, organização das idéias e argumentação.

Os alunos relataram que deveriam economizar água nas atividades que eles desenvolviam em casa, como tomar banho menos demorado e escovar os dentes com a torneira fechada, ou seja, eles desenvolveram bem o tema. O que se notou nas redações foi à preocupação em se preservar água, usando-a racionalmente para colaborar com as futuras gerações. Já na correção gramatical alguns erros foram encontrados com relação a abreviar palavras ou escrevê-las erroneamente, como KSA ao invés de CASA ou VC ao invés de VOCÊ, por exemplo.

Isso pode ser justificado devido à utilização de sites de bate papo na internet, que está distorcendo a escrita de muitos adolescentes e jovens.

Sanches (2006) cita os Parâmetros Curriculares Nacionais (PCN) do Ensino Médio enfatizando que, nesse período escolar, os alunos devem desenvolver muitas habilidades e competências como buscar informações, pesquisar de forma a aprender e criar e assim continuar estudando, sendo que as finalidades do ensino da Língua Portuguesa são o aprofundamento e a consolidação do estudo, por meio dos conhecimentos adquiridos no Ensino Fundamental e utilizando este estudo como instrumento de comunicação.

Ainda segundo Sanches (2006), menciona que os PCN também apontam para o caráter sociocognitivo-interacional da linguagem como opção metodológica de verificação do 
saber lingüístico do aluno. Trata-se de um ponto de partida para a decisão daquilo que será desenvolvido, cujo referencial é o valor da linguagem nos diferentes segmentos sociais [SANCHES, 2006, p. 40].

\section{Conclusões}

Nesta pesquisa verificou-se que é possível desenvolver, com alunos do ensino médio, um estudo sobre água potável enfocando conteúdos químicos. Além de possibilitar uma reflexão sobre as formas racionais de utilização da água potável e ainda o desenvolvimento da responsabilidade sócio-ambiental para com os recursos hídricos.

A maioria dos alunos que participou desse trabalho considerou que a escassez de água é um fato alarmante e que todos devem rever suas atitudes no que se refere ao desperdício de água. Assim, podemos salientar a importância de integrar as aulas a linguagens do cotidiano dos alunos, ajudando-os a conduzir o processo de aprendizagem mais facilmente e de forma descontraída, a fim de chamar mais a atenção dos estudantes e gerar discussões sobre o tema abordado.

A associação do estudo da água potável ao cotidiano dos alunos através da contextualização e interdisciplinaridade facilitou o aprendizado dos conceitos que para os alunos eram considerados complexos, contribuindo para uma aprendizagem mais significativa.

Fica evidente que se faz necessário para o educador trabalhar com material didático diversificado e estratégias metodológicas diferenciadas para motivar e conquistar aos alunos, promovendo neles o prazer em se estudar Química.

Esse estudo poderá tornar-se uma referência para se trabalhar esse tipo de abordagem, para os educadores que veem no ensino de Química, inúmeras possibilidades de capacitar o aluno para a cidadania.

\section{Referências}

1. BRASIL. Portaria $N^{\circ} 518$, de 25 de Março de 2004. Estabelece os procedimentos e responsabilidades relativos ao controle e vigilância da qualidade da água para consumo humano e seu padrão de potabilidade, e dá outras providências. Diário Oficial da União; Poder Executivo,
Brasília, 26 mar. 2004 Disponível em: $<$ http://e-

legis.anvisa.gov.br/leisref/public/showAct.ph p?id=22322\&word>. Acesso: 08 abr. 2009, 21:25:15.

2. DANIEL, L. A. Processos de desinfecção e desinfetantes alternativos na produção de água potável. Projeto PROSAB 2 Programa de pesquisa em saneamento básico. Rio de Janeiro: RiMa Artes e Textos, 2001. 155 p. il..

3. ELISIE, M. G. M.. Diagnóstico da percepção ambiental dos alunos. Saneamento Ambiental, São Paulo, $n^{\circ} 132$, p. 35 - 36. jan./fev. 2008.

4. FERREIRA, V. F.. As tecnologias interativas no ensino. Quím. Nova [online]. 1998, vol. 21, $\mathrm{n}^{\circ}$. 6, p. 780 - 786. Disponível em: <http://www.scielo.br/pdf/qn/v21n6/2913.pdf >. Acesso: 24 set. 2009, 22:50:00.

5. GOIÁS. Saneamento de Goiás S/A. Superintendência de Recursos Humanos. Gerência de Desenvolvimento de Pessoal. Operação de estação de tratamento de água: manual. Goiânia, 2006. 150 p..

6. LAGE, F., NOGUEIRA, M. G. e FORESTI, M. C. P.. A importância do tema água doce no ensino fundamental: uma proposta de aulas teórico - práticas. 19 p.. Disponível em: <http://www.unesp.br/prograd/PDFNE2004/ artigos/eixo2/aimportanciadotemaguadoce. pdf>. Acesso em: 26 mai. 2009, 22:21:00.

7. LAURENTI, A.. Qualidade da água I. Florianópolis: Imprensa Universitária, 1997. $89 \mathrm{p..}$

8. MACIEL, L. S. B. e DOMINGUES, A. L.. A água e seus múltiplos enfoques no ensino de Ciências no nível fundamental. Acta Scientiarum, Maringá, 23 (1): p.183 - 195, $2001 . \quad$ Disponível em: <http://www.periodicos.uem.br/ojs/index.php /ActaSciHumanSocSci/article/viewPDFInter stitial/2774/1899>. Acesso em: 30 de mar. 2009, 23:40:15.

9. MOREIRA M. A.. Mapas conceituais e aprendizagem significativa. Instituto de Física - UFRGS. Porto Alegre - RS. 1997. Disponível em: <http://www2.iq.usp.br/docente/famaxim/dis ciplina/integrada/mapasport-Moreira.pdf>. Acesso em: 30 set. 2009, 23:04:15.

10. MORAN, J. M.. O Vídeo na Sala de Aula. Comunicação \& Educação: São Paulo, Ed. Moderna, [2]: 27 a 35, jan./abr. De 1995.

11. SANCHES, Y. P.. Um estudo das redações no Ensino Médio: perspectivas 
para o ensino de Língua Portuguesa. 2006. 174f. Dissertação (Mestrado em Língua Portuguesa) - Estudos de PósGraduados em Língua Portuguesa, Pontifícia Universidade Católica de São Paulo, São Paulo, 2006. Disponível em: $<$ http://www.sapientia.pucsp.br//tde_busca/a rquivo.php?codArquivo=4097>. Acesso em: 26 set. 2009, 00:15:15.

12. SOUZA, A. C. de et al.. Vídeos do YouTube como ferramenta didática no ensino superior de Publicidade e Propaganda. In: CONGRESSO BRASILEIRO DE CIÊNCIAS DA COMUNICAÇÃO, 32, 2009, Curitiba. Resumos... Curitiba: Intercom - Sociedade Brasileira de Estudos Interdisciplinares da Comunicação, 2009. 13 p.. Disponível em: $<$ http://www.intercom.org.br/papers/nacionai s/2009/resumos/R4-0720-1.pdf>. Acesso em: 28 set. 2009.
13. TRIPP, D.. Pesquisa-ação: uma introdução metodológica. Educ. Pesqui. [online]. 2005, vol.31, n.3, pp. 443-466. Disponível em: $<$ http://www.scielo.br/pdf/ep/v31n3/a09v31n 3.pdf>. Acesso em: 26 set. 2009.

14. You Tube. Água, Fonte de Vida! Duração: 6 min.: son., color.. com narrativa. Didático. [online]. Disponível em: $<$ http://www.youtube.com/watch? v=0VIQqZGjsik>. Acesso: 30 mai. 2009.

15. ZUIN, V. G., IORIATTI, M. C. S. e MATHEUS, C. E.. O Emprego de parâmetros físicos e químicos para a avaliação da qualidade de águas naturais: uma proposta para a educação Química e Ambiental na perspectiva CTSA. Química Nova na Escola. Vol. $31 \mathrm{~N}^{\circ} 1$, p. 1-6, Fev.2009. Disponível em:< http://qnesc.sbq.org.br/online/qnesc31_1/02 -QS-5507.pdf>. Acesso em: 26 mar. 2009.

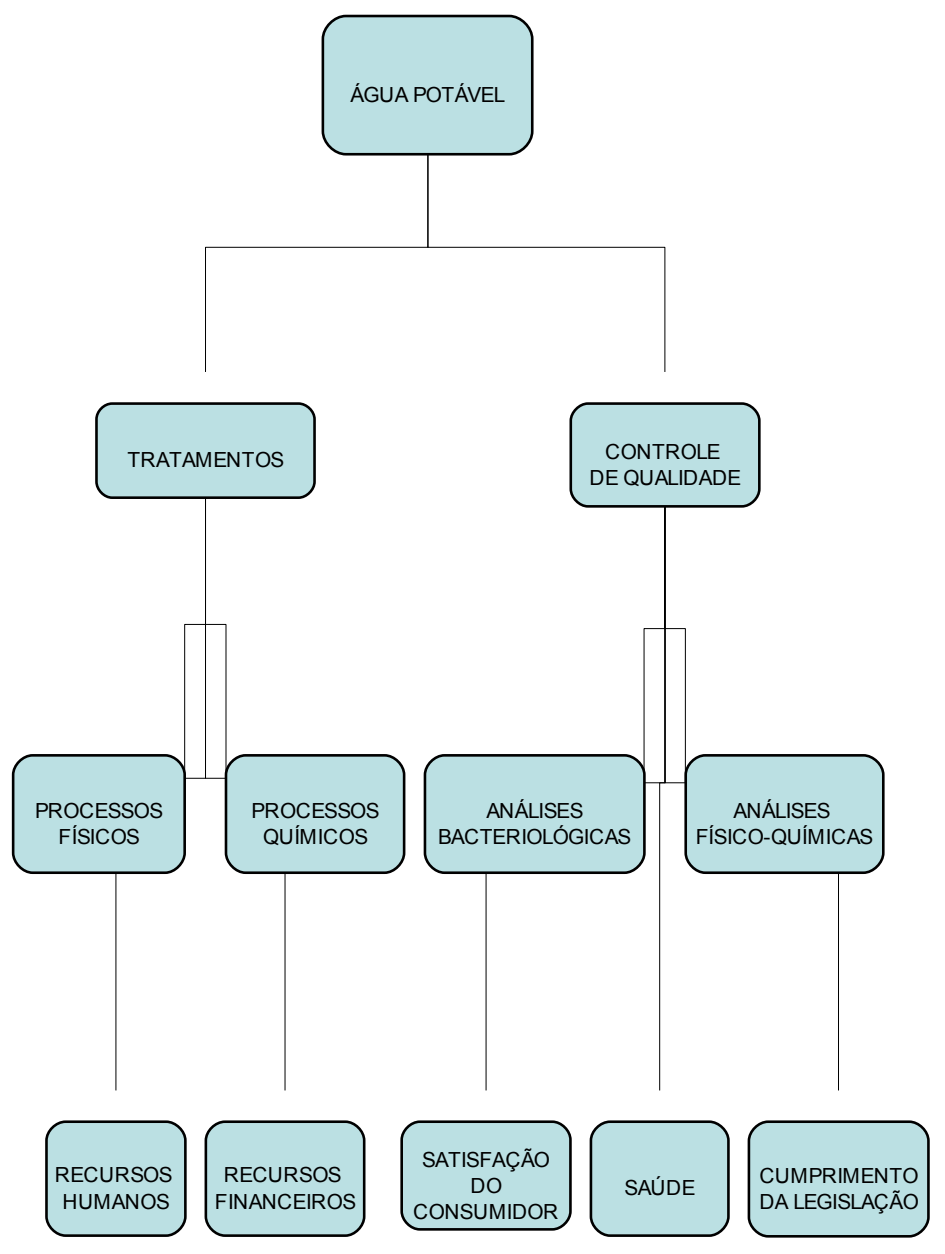

Figura 7 - Mapa conceitual utilizado na aula. 


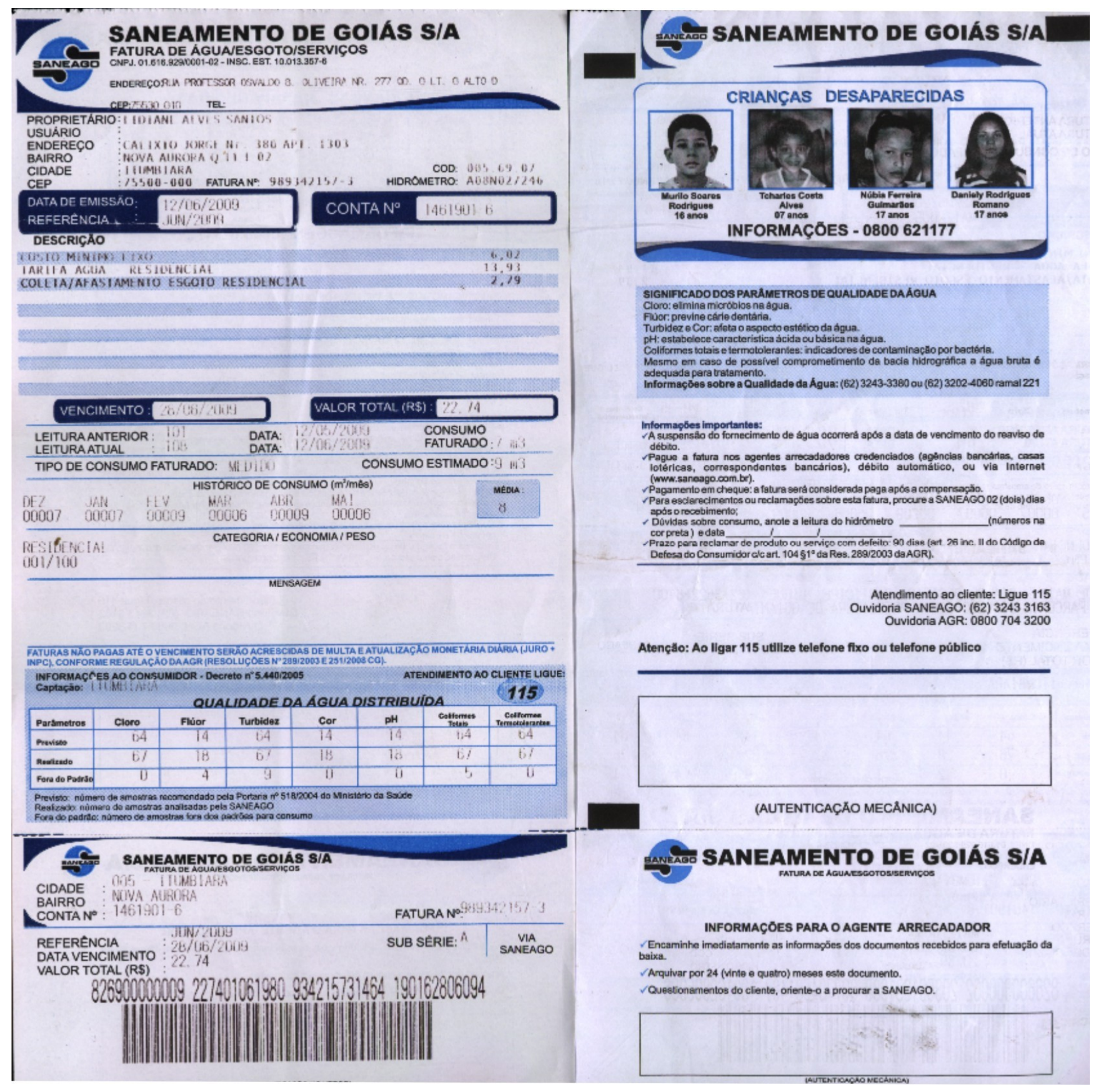

Figura 8 - Conta de água trabalhada com os alunos.

Periódico Tchê Química. Vol. 7 - N. 14 - AGO/2010. Porto Alegre - RS. Brasil.

The Periódico Tchê Química (ISSN: 1806-0374; 2179-0302) is an open-access journal since 2004. Journal DOI: 10.52571/PTQ. http://www.tchequimica.com.

This text was introduced in this file in 2021 for compliance reasons.

() The Author(s)
OPEN ACCESS. This article is licensed under a Creative Commons Attribution 4.0 (CC BY 4.0) International License, which permits use, sharing, adaptation, distribution, and reproduction in any medium or format, as long as you give appropriate 